\title{
Attitudes and opinions of pregnant women who are not offered cystic fibrosis carrier screening
}

\author{
Liane Ioannou ${ }^{1,2}$, John Massie ${ }^{1,3,4}$, Sharon Lewis ${ }^{1}$, Veronica Collins ${ }^{5}$, Belinda McClaren ${ }^{1}$ and \\ Martin B Delatycki ${ }^{\star 1,2,4,6}$
}

Cystic fibrosis (CF) is the most common severe, autosomal recessive disease among Caucasians. A population-based CF carrier screening programme was implemented in Victoria, Australia, in 2006. Carrier screening for CF is currently only offered in the private health system. The aim of this study was to determine the attitudes and opinions of pregnant women in the public health system, towards screening for CF. Pregnant women were recruited in the antenatal clinics of two public hospitals, and invited to participate in the study. Results of this study were compared with previous studies where screening for CF carrier status was offered. Of the participants $(n=158)$, the majority were aged $25-34$ years old $(66.1 \%)$ and were Caucasian (45.8\%). Compared with those who were offered screening (reported in previous studies) participants in the current study were younger, had a lower level of education and a lower income. Knowledge was significantly lower in those who were not offered screening compared with those who were offered screening. The majority of participants believe CF carrier screening should be offered in the public health system (80.5\%) and almost half would have liked to receive an offer of screening during their current pregnancy (49.7\%). In order for the programme to be equitable, screening for CF carrier status needs to be offered in both the public and private health system and ideally should be at no cost to the user.

European Journal of Human Genetics (2014) 22, 859-865; doi:10.1038/ejhg.2013.267; published online 20 November 2013

Keywords: genetic screening; cystic fibrosis; cystic fibrosis carrier screening; attitudes

\section{INTRODUCTION}

Genetic screening is a test performed for early detection of a hereditary disease, predisposition to a hereditary disease or to determine whether a healthy individual carries a predisposition that may cause disease in offspring. ${ }^{1}$ A carrier is an individual who has a heterozygous mutation for an autosomal or X-linked recessive genetic condition, such that they are not at risk of the condition themselves but are at higher risk of having a child with the condition. Carrier screening can identify couples in which both individuals are carriers, and therefore have a high risk of having a child with the condition tested for. The couple can then be informed about available reproductive options.

Population-based screening is directed towards the whole population with the aim being to counsel and test as many individuals at genetic risk as possible regardless of whether or not they have a family history of the genetic disorder. In order to justify population-based carrier screening for particular diseases, the World Health Organisation (WHO) proposed certain criteria that must be met. These include that the condition is an important health problem, testing can be performed to determine carrier status with known test sensitivity and reproductive options are available to prevent the birth of a child with the disease. ${ }^{2}$

Cystic fibrosis (CF) is an example of a genetic disease that satisfies the WHO requirements for population-based screening. It is the most common, severe, autosomal recessive disease in Caucasians, with a birth frequency of 1 in 2500-3500 and a carrier frequency of 1 in $25 .^{3}$
$\mathrm{CF}$ is the result of mutations in the CF transmembrane conductance regulator (CFTR) gene and since the discovery of the gene in 1989, more than 1900 alterations have been identified. The most frequently occurring mutation in the Caucasian population is p.F508del, accounting for $\sim 70 \%$ of all mutations present. ${ }^{4}$

The main clinical features of CF are suppurative lung disease, pancreatic exocrine insufficiency and elevated sweat electrolytes. There is currently no cure for CF but various therapies have markedly improved lifespan. Treatment involves daily therapies including chest physiotherapy, antibiotics, pancreatic enzymes and a high-calorie diet. $^{5}$ The suppurative lung disease is progressive and largely responsible for the reduced life expectancy. ${ }^{6}$ The median life expectancy is 37 years. ${ }^{7}$ Lung transplantation is possible in some patients. Although the outcomes of lung transplant in individuals with CF are continually improving, the 5-year survival post transplantation is still only $50 \% .^{8}$

Cascade testing is highly accurate and more sensitive than population carrier screening for $\mathrm{CF}$, as the familial mutations are usually known. ${ }^{9}$ However, it has been shown that cascade testing is only taken up by $2-3$ relatives per proband. ${ }^{10}$ Also the efficacy, which is defined as the total number of carriers identified in a population, is lower in cascade testing than in population screening for $\mathrm{CF}^{11}$ This is due to the fact that more than $95 \%$ of carriers have no family history of CF. ${ }^{12,13}$

In 1999, the National Institute of Health recommended that CF carrier screening be offered to all pregnant women and couples

${ }^{1}$ Bruce Lefroy Centre for Genetic Health Research, Murdoch Childrens Research Institute, Parkville, VIC, Australia; ${ }^{2}$ Department of Medicine, Monash University, Clayton, VIC, Australia; ${ }^{3}$ Department of Respiratory Medicine, Royal Children's Hospital, Parkville, VIC, Australia; ${ }^{4}$ Department of Paediatrics, University of Melbourne, Parkville, VIC, Australia; ${ }^{5}$ Andrology Australia, Monash Institute of Medical Research, Clayton, VIC, Australia; ${ }^{6}$ Clinical Genetics, Austin Health, Heidelberg, VIC, Australia

${ }^{*}$ Correspondence: Professor MB Delatycki, Bruce Lefroy Centre for Genetic Health Research, Murdoch Childrens Research Institute, 10th Floor, Royal Children's Hosptial, Flemington Road, Parkville, VIC 3052 Australia. Tel: +61 39496 4355; Fax: +61 39496 4385; E-mail: martin.delatycki@ghsv.org.au

Received 18 February 2013; revised 5 October 2013; accepted 24 October 2013; published online 20 November 2013 
planning a pregnancy. The American College of Medical Genetics and the American College of Obstetricians and Gynecologists subsequently released similar recommendations. ${ }^{14,15}$ The Human Genetic Society of Australasia position paper states that 'all pregnant women and couples planning a pregnancy should be made aware of the availability of carrier screening for CF. ${ }^{16}$

In Victoria, Australia, a population-based CF carrier screening programme was implemented by the Victorian Clinical Genetics Services in 2006. The programme offers screening to women or couples before or during the early stages of pregnancy via obstetricians and general practitioners in the private health sector. It is currently a fee-for-service programme with each test costing AUD \$220. During the first 3 years of the programme (2006-2008), 3200 individuals were screened, all partners of carriers were tested and carrier couples used the information received to make reproductive decisions. ${ }^{17}$

We have studied a number of aspects of our programme, including the attitudes and outcomes of individuals who accepted CF carrier screening ${ }^{18}$ and compared the response with individuals who declined CF carrier screening. ${ }^{19}$ These studies reflected the attitudes of people offered screening in the private obstetric sector and were biased towards women of higher education and family income than the general population. There are limited data about CF carrier screening from women attending public obstetric services.

The aim of this present study was to explore the attitudes and opinions of pregnant women in the public health system who were not offered CF carrier screening and compare these with the attitudes and opinions of individuals who were offered CF carrier screening from our previous studies. ${ }^{18,19}$

\section{MATERIALS AND METHODS}

\section{Participants}

Pregnant women ( $<16$ weeks' gestation) were recruited in the waiting rooms of antenatal clinics at two public hospitals in Melbourne, Victoria. Women who were unable to read or write English or required an interpreter were excluded from the study.

\section{Questionnaire development}

Interviews were conducted to assist with the development of the questionnaire. Interviews were semi-structured, $\sim 10 \mathrm{~min}$ in duration and were conducted in the waiting room of the clinic. The interview schedule is included as an appendix. Interviews were recorded and transcribed. Content analysis was used to analyse the data.

\section{Questionnaire \\ The purpose-designed questionnaire assessed the following domains: demo- graphic characteristics; screening history; knowledge of CF and CF carrier screening; reasons that may influence the decision to have screening; attitude towards screening for genetic conditions; attitude towards CF carrier screening. The demographics, knowledge questions and factors influencing the decision to have screening were sourced from the questionnaires used in the previous studies of individuals who were offered CF carrier screening, to allow for comparison. ${ }^{18,19}$ The questionnaire can be viewed at http://www.mcri.edu.au/ notofferedcfscreening/.}

\footnotetext{
Analysis

Data analysis of questionnaires was conducted using SPSS (Windows, version 17.0; SPSS, Chicago, IL, USA). Preliminary descriptive analysis generated frequency data to elicit a description of participants.

Potential factors influencing the decision to have screening were measured on 5-point Likert scales. For analysis, points ' 1 ' and ' 2 ' were combined to form the category 'did not influence', the middle point ' 3 ' remained neutral, while points ' 4 ' and ' 5 ' were combined to form the category 'influenced'.
}

The data from the current study of participants who were not offered CF carrier screening were compared with data from the previous studies evaluating the attitudes and outcomes for individuals who had accepted and declined an offer of screening. ${ }^{18,19}$ Analysis of categorical variables was undertaken using $\chi^{2}$ analyses and, for continuous variables, differences in means between groups were assessed using $t$-tests. A $P$-value $<0.05$ was considered statistically significant.

\section{Ethics committee approval}

This study was approved by the Southern Health Human Research Ethics Committee, Victoria, Australia (HREC\#10084B).

\section{RESULTS}

\section{Interviews}

Between January and June 2011, nine interviews were conducted. The main themes to arise were: reasons for screening, reasons against screening and information/education. A flow chart of the themes and quotes are shown in Figure 1.

\section{Questionnaire response rate}

Between July 2011 and August 2012, a total of 187 pregnant women were approached in the waiting room at two antenatal clinics. Of the 187 women approached, two directly declined to participate while the rest were administered questionnaires to complete in the waiting room. Of the 185 questionnaires distributed, a total of 158 completed questionnaires were received, giving a response of $85 \%$.

\section{Demographics of respondents}

The demographics are presented in Table 1. Those who were not offered screening were significantly younger in age $\left(\chi^{2}=97.65\right.$, $P<0.01, \mathrm{df}=5)$, had a lower level of education $\left(\chi^{2}=62.64, P<0.01\right.$, $\mathrm{df}=5)$ and a lower household income $\left(\chi^{2}=113.67, P<0.01, \mathrm{df}=4\right)$ compared with those who were offered screening. There is also a significant difference in ethnicity between the two groups, with the majority of those who were not offered screening being of Asian descent and those who were offered screening being of Australian and European descent $\left(\chi^{2}=97.91, P<0.01, \mathrm{df}=5\right)$ (Table 1$)$.

\section{Knowledge of $\mathrm{CF}$ and screening}

Participants were asked to select true, false or unsure as a response to 15 knowledge statements regarding CF and carrier screening. The majority of participants $(53.5 \%)$ answered between $1-5$ of the knowledge statements correctly. All fifteen knowledge statements were answered correctly by less than $50 \%$ of participants. Thirteen of the 15 knowledge questions were answered correctly significantly more often by those who were offered screening (accepted and declined) compared with those who were not offered screening. Knowledge of $\mathrm{CF}$ and carrier screening was significantly lower in those who were not offered screening compared with those who were offered screening $(t=3.32, P<0.01)$ (Figure 2$)$.

More than $50 \%$ of participants selected unsure as a response to all fifteen knowledge statements. Those who were not offered screening selected unsure as a response to knowledge statements more often than those who were offered screening for all of the fifteen knowledge questions.

Potential factors influencing the decision to have genetic screening Participants were asked to rate factors that might influence their decision to have carrier screening for genetic conditions on a Likert scale. The factors most commonly rated as potentially influencing the decision to have screening were partner's opinion, $n=88(59.5 \%)$ and 


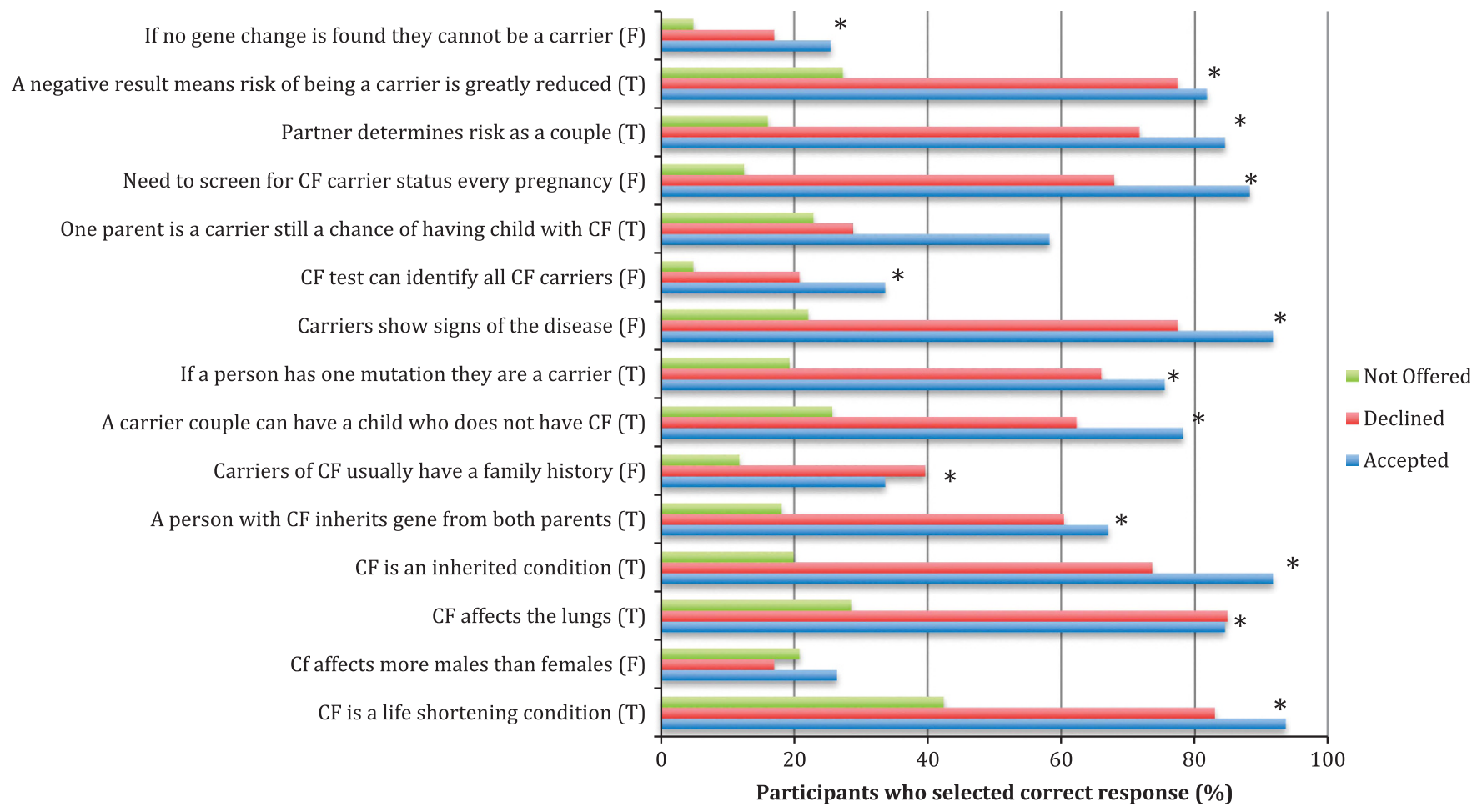

Figure 1 Flow chart of the themes arising from semi-structured interviews and illustrative quotes from participants. ${ }^{*} P<0.05$ for comparison of proportions in current versus previous studies using $\chi^{2}$ test.

lack of family history $n=68(46.3 \%)$. Believing that they would not consider a termination of pregnancy for CF was identified as an influential factor for $55(38.7 \%)$ participants. Fifty-five $(36.9 \%)$ participants considered that their doctor's recommendation or cost of the test (89 (61.4\%) participants) would not influence their decision to have screening (Figure 3 ).

Three factors were considered to be influential in the decision by a significantly greater proportion of those who were not offered and declined screening than those who accepted screening. These were: (i) family history of $\mathrm{CF}\left(\chi^{2}=59.80, P<0.01, \mathrm{df}=3\right)$; (ii) family history of other genetic conditions $\left(\chi^{2}=63.20, P<0.01, \mathrm{df}=3\right)$; and (iii) perceived susceptibility of being a carrier of CF $\left(\chi^{2}=54.09\right.$, $P<0.01, \mathrm{df}=3$ ). Doctor's recommendation was an influencing factor more often among those who had screening than those who declined or were not offered screening $\left(\chi^{2}=39.78, P<0.01, \mathrm{df}=3\right)$ (Figure 4).

\section{Screening history}

Eighty-one $(52.6 \%)$ of participants sought medical advice prior to pregnancy, with $26(32.1 \%)$ of these having discussed genetic issues. In their current pregnancy, $124(81 \%)$ stated that they had screening for trisomy 21 and $26(16.5 \%)$ had been offered testing for other genetic conditions. Fourteen $(53.8 \%)$ of these stated they were offered screening for thalassaemia, with 10 being tested.

\section{Attitude towards screening for genetic conditions}

One hundred and fifteen (75.7\%) believe screening for genetic conditions should be available regardless of having a family history. Of these, $50(48.1 \%)$ stated that before pregnancy would be the best time to offer screening and $79(68.7 \%)$ wished they had been offered screening during their current pregnancy.

\section{Attitude towards carrier screening for CF}

Eighty-three (54.2\%) had heard of CF prior to completing the questionnaire. One hundred and twenty $(80.5 \%)$ participants believe screening for CF should be offered in the public health system, with only $3(2.0 \%)$ participants stating it should not be offered, and the remaining $26(17.4 \%)$ being unsure.

Fifty-two (36.9\%) participants believe that CF carrier screening should be free of charge. When asked if they would have liked to have received an offer of CF carrier screening during their current pregnancy, $72(49.7 \%)$ stated they would; 60 (83.3\%) would have accepted the offer. Twenty five (17.2\%) stated that they would not like to have been offered CF carrier screening during their current pregnancy, but $15(60.0 \%)$ of these would have accepted the offer prior to pregnancy. The remaining $48(33.1 \%)$ were unsure if they would have liked to have been offered screening for CF.

\section{DISCUSSION}

The majority of pregnant women in the Australian public hospital system in this study believed that CF carrier screening should be offered in the public hospital system or by family doctors. Most believed screening should be offered before pregnancy, but many would have taken up an offer of screening in the current pregnancy if asked. The cost of screening was an important factor, and it was thought that it should be available for less than AUD \$50 per test.

Knowledge of CF and screening was significantly lower in those who were not offered screening compared with those who were offered screening, illustrating that receiving an offer of screening may increase knowledge. Factors that may potentially influence a participant's decision to accept an offer of screening were partner's opinion, lack of family history and perceived susceptibility. These were significantly different to those who accepted an offer of screening. ${ }^{18,19}$ 
Table 1 Comparison of demographic characteristics of those who were offered screening and those who were not offered screening for CF carrier status

No. of Participants (\%)

\begin{tabular}{|c|c|c|c|c|}
\hline Demographic & Categories & Offered $^{a} n=166$ & Not offered $n=158$ & $\begin{array}{r}\text { Chi square statistic (degrees } \\
\text { and } P \text {-value }\left(\chi^{2}\right)\end{array}$ \\
\hline \multirow[t]{2}{*}{ Gender } & Male & $3(1.8)$ & $0(0.0)$ & 2.88 \\
\hline & Female & $163(98.2)$ & $158(100.0)$ & $P=0.09$ \\
\hline \multirow[t]{6}{*}{ Age (in years) } & $<20$ & $0(0.0)$ & $5(3.2)$ & $97.65(\mathrm{df}=5)$ \\
\hline & $20-24$ & $0(0.0)$ & $28(17.9)$ & ${ }^{*} P=0.00$ \\
\hline & $25-29$ & $14(8.6)$ & $50(32.1)$ & \\
\hline & $30-34$ & $61(37.4)$ & $53(34.0)$ & \\
\hline & $35-39$ & $73(44.8)$ & $19(12.2)$ & \\
\hline & $40+$ & $15(9.2)$ & $1(0.6)$ & \\
\hline \multirow[t]{6}{*}{ Highest completed level of education } & Year 11 or less & $3(1.9)$ & $24(15.4)$ & $62.64(\mathrm{df}=5)$ \\
\hline & Finished secondary school & $8(5.0)$ & $36(23.1)$ & ${ }^{*} P=0.00$ \\
\hline & Trade/Apprenticeship & $2(1.2)$ & $3(1.9)$ & \\
\hline & College certificate or diploma & $29(18.0)$ & $41(26.3)$ & \\
\hline & University degree & $116(72.0)$ & $51(32.6)$ & \\
\hline & Other & $3(1.9)$ & $1(0.6)$ & \\
\hline \multirow[t]{9}{*}{ Occupation } & Managers & $37(23.3)$ & $10(6.9)$ & $\mathrm{s} 84.82(\mathrm{df}=8)$ \\
\hline & Professionals & $61(38.4)$ & $12(8.3)$ & ${ }^{*} P=0.00$ \\
\hline & Technician \& Trade & $11(6.9)$ & $6(4.2)$ & \\
\hline & Community \& Personal Service & $30(18.9)$ & $45(31.3)$ & \\
\hline & Clerical/Administration & $13(8.2)$ & $28(19.4)$ & \\
\hline & Sales & $4(2.5)$ & $14(9.7)$ & \\
\hline & Machinery Operators \& Drivers & $0(0.0)$ & $3(2.1)$ & \\
\hline & Labourers & $0(0.0)$ & $4(2.8)$ & \\
\hline & Unskilled & $3(1.9)$ & $22(15.3)$ & \\
\hline \multirow[t]{5}{*}{ Household Income (in AUD \$1000s) } & $20-40$ & $3(1.9)$ & $43(29.7)$ & $113.67(\mathrm{df}=4)$ \\
\hline & $41-60$ & $8(5.1)$ & $38(26.2)$ & ${ }^{*} P=0.00$ \\
\hline & $61-80$ & $14(8.9)$ & $25(17.2)$ & \\
\hline & $81-100$ & $22(14.0)$ & $15(10.3)$ & \\
\hline & $>100$ & $110(70.1)$ & $24(16.6)$ & \\
\hline \multirow[t]{6}{*}{ Ethnicity } & Australia & $100(61.7)$ & $33(22.9)$ & $97.91(\mathrm{df}=5)$ \\
\hline & America & $1(0.6)$ & $5(3.5)$ & ${ }^{*} P=0.00$ \\
\hline & Europe & $52(32.1)$ & $28(19.4)$ & \\
\hline & Asia & $6(3.7)$ & $59(41.0)$ & \\
\hline & New Zealand/Islander & $3(1.9)$ & $17(11.8)$ & \\
\hline & Africa & $0(0.0)$ & $2(1.4)$ & \\
\hline \multirow[t]{2}{*}{ Affinity with a Religion } & Yes & $73(45.1)$ & $74(47.1)$ & 0.35 \\
\hline & No & 89 (54.9) & $79(50.3)$ & $P=0.56$ \\
\hline \multirow[t]{2}{*}{ Partner at time of testing/participation } & Yes & $161(98.8)$ & $141(90.4)$ & 11.12 \\
\hline & No & $2(1.2)$ & $15(9.6)$ & ${ }^{*} P=0.00$ \\
\hline \multirow[t]{2}{*}{ Pregnant at time of testing/participation } & Yes & $144(88.3)$ & $158(100.0)$ & 19.58 \\
\hline & No & 19 (11.7) & $0(0.0)$ & ${ }^{*} P=0.00$ \\
\hline \multirow[t]{4}{*}{ Number of children at time of testing } & 0 & $47(29.2)$ & $77(50.0)$ & $14.76(\mathrm{df}=3)$ \\
\hline & 1 & $76(47.2)$ & $55(35.7)$ & ${ }^{*} P=0.00$ \\
\hline & 2 & $30(18.6)$ & 17 (11.0) & \\
\hline & 3 or more & $8(5.0)$ & $5(3.2)$ & \\
\hline
\end{tabular}

aData from previous studies. ${ }^{18,19}$

Note: ${ }^{*} P<0.05$ for comparison of proportions in current versus previous studies using $\chi^{2}$ test. Not all participants answered all questions and this is reflected in the percentages provided.

As the three research groups were not assessed contemporaneously, some groups may have been exposed to more information on CF and screening, for example through the media, and this may have had some impact on the outcome of the study.

The significant difference in the demographics between the offered and not offered groups reflects the private and public health settings in which participants were recruited. Compared with our previous studies, participants from the present study were recruited in the public health system and were younger, had a lower level of education, lower household income and the majority were of Asian descent. These demographic findings may provide potential barriers to the implementation of the routine offer of CF carrier screening. Previously we have shown that uptake of CF carrier screening is associated with maternal age, with those who decline screening being significantly younger than those who accepted it. ${ }^{19}$ A higher level of education has also been associated with higher uptake of 
If no gene change is found they cannot be a carrier (F)

A negative result means risk of being a carrier is greatly reduced (T)

Partner determines risk as a couple (T)

Need to screen for CF carrier status every pregnancy (F)

One parent is a carrier still a chance of having child with CF (T)

CF test can identify all CF carriers (F)

Carriers show signs of the disease $(\mathrm{F})$

If a person has one mutation they are a carrier (T)

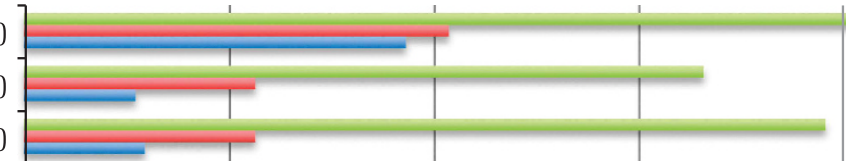

(T)

(F)

(T)

A carrier couple can have a child who does not have $\mathrm{CF}$

Carriers of CF usually have a family history

(T)

A person with $\mathrm{CF}$ inherits gene from both parents (T)

CF is an inherited condition (T)

$\mathrm{CF}$ affects the lungs $(\mathrm{T})$

Cf affects more males than females (F)

$\mathrm{CF}$ is a life shortening condition $(\mathrm{T})$

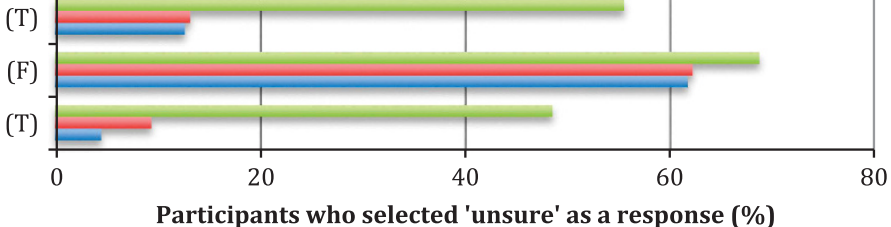

Not Offered

- Declined

Accepted

Participants who selected 'unsure' as a response (\%)

Figure 2 Comparison of knowledge of those who were offered screening (accepted and declined) and those who were not offered screening for CF carrier status.

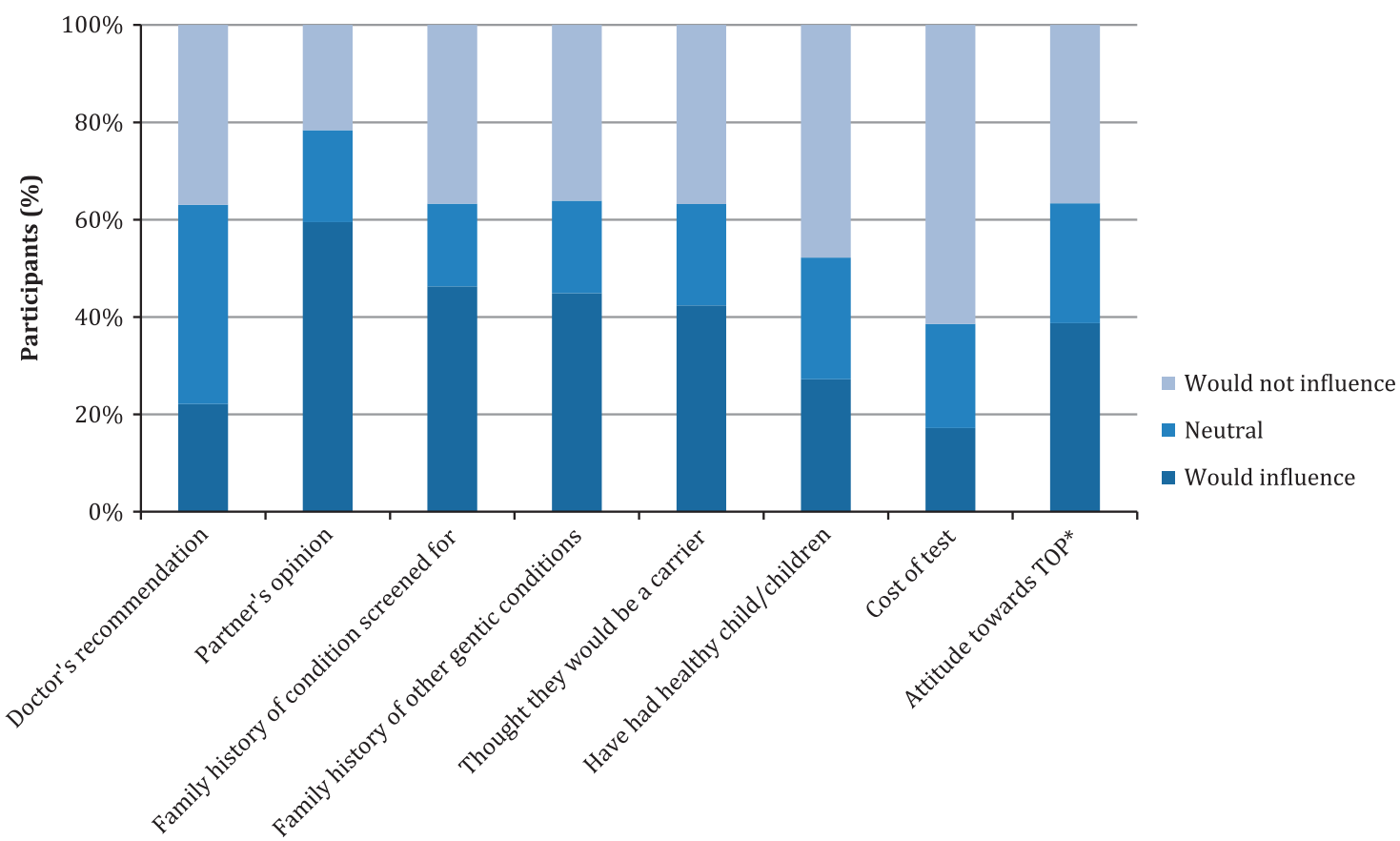

Figure 3 Potential factors that may influence the decision whether or not woman would accept an offer of CF carrier screening. ${ }^{*}$ TOP, termination of pregnancy.

screening. ${ }^{20,21}$ Knowledge of CF and screening is also higher in those with a higher level of education. ${ }^{22}$ Low income could also be a potential barrier with evidence showing that uptake is associated with high income. ${ }^{21}$ The current cost of the test in Victoria is AUD \$220. Together with out of pocket costs for screening for trisomy 21 and other pregnancy-related tests, CF carrier screening may not be affordable to many couples in the public hospital system with an average household income of AUD \$20-40000.
The demographic finding of $40 \%$ of the participants identifying as of Asian origin has important implications for a population CF carrier programme. As the participants in the study were required to read and write English, it excluded a number of women from non-English speaking backgrounds and therefore our study population is likely to under-represent the ethnic mix attending a public obstetric service. In addition to the issues of education and income discussed above, CF is less common in 


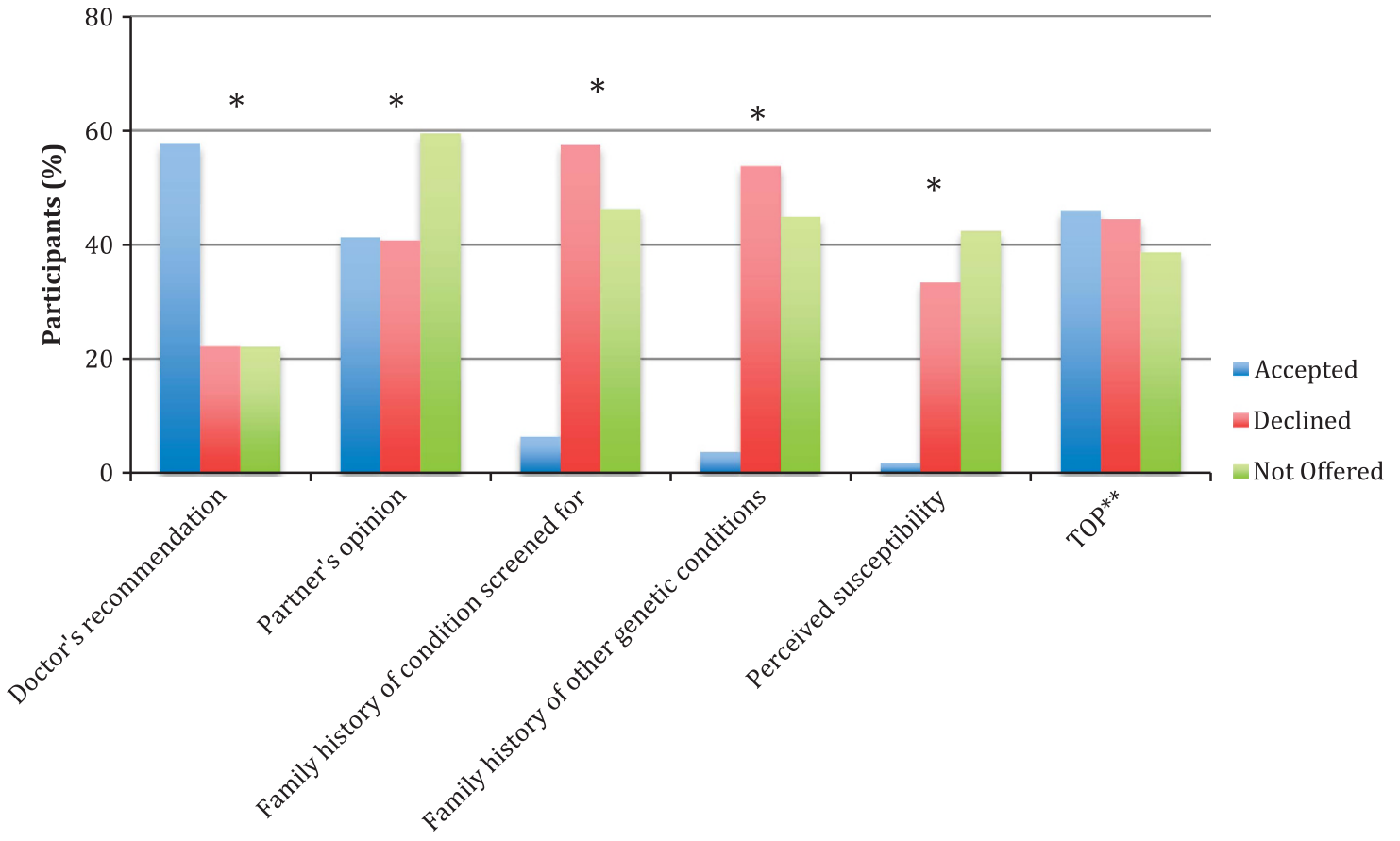

Figure 4 Comparison of potential factors that may influence the decision to have $\mathrm{CF}$ carrier screening and factors that influenced the decision to have $\mathrm{CF}$ carrier screening between those who were offered screening (accepted and declined) and those who were not offered screening for CF carrier status. ${ }^{*} P<0.05$ for comparison of proportions in current versus previous studies using $\chi^{2}$ test. ${ }^{* *}$ TOP, termination of pregnancy.

non-Caucasian people so that baseline awareness of the condition is likely to be lower.

Furthermore, the ethnic diversity in this population will affect the sensitivity of the screening test with the mutations tested for in the current screening panel being the most common mutations in the Caucasian population. ${ }^{23}$ This complicates pre-test information about relevance of $\mathrm{CF}$ screening to certain ethnic populations and affects residual risk calculations. However, identification of ethnic background can be difficult and not offering carrier screening on the basis of race has ethical implications. For this reason, the pre-test information in our CF carrier screening programme includes data on the incidence of $\mathrm{CF}$ in different populations and the associated residual risk estimates.

Participants were asked to rate factors that may influence their decision to accept or decline an offer of genetic carrier screening. However, this study involved a hypothetical offer of CF carrier screening; therefore, although the results are still important in determining predicted attitudes and behaviours towards screening, these might change upon receipt of an actual offer of screening.

The main factors that influenced their decision with regard to having screening were: partner's opinion, family history of the specific condition or other genetic conditions and perceived susceptibility. These influencing factors, with the exception of partner's opinion, were found to be important in the decision to decline CF carrier screening. ${ }^{19}$ Therefore, if offered CF carrier screening, our data suggest that the majority of women in the public hospital system would decline the offer based on a lack of family history and low perceived susceptibility. ${ }^{24}$

One of the other interesting outcomes of this study was the number of women who saw health professionals prior to pregnancy. Preconception carrier screening, while being the preferred time to screen, has previously been associated with low uptake due to a lack of preconception health-care setting in which to offer screening. ${ }^{25}$
However, the results show that almost half of the participants in this study sought medical advice prior to pregnancy from their GP or obstetrician. This was also shown in another Australian study with a higher uptake of testing at a family planning clinic compared with general practice. ${ }^{26}$

The majority of participants indicated that they would prefer to receive an offer of CF carrier screening and pre-test information from their GP. Therefore, health professionals are key stakeholders in CF carrier screening, as they are the gatekeepers of screening and their attitudes, opinions and knowledge in regard to CF carrier screening are significant in the effectiveness of offering population-based screening. There is also evidence that doctor's opinion and recommendation is an influencing factor in the decision to accept an offer of screening. ${ }^{18,21,24,27}$

There are barriers to screening from the health-care providers' perspective, including costs, time constraints and availability of supporting services. Another barrier to offering CF carrier screening to patients is a lack of knowledge and experience in regard to CF and genetic screening, with health professionals lacking confidence in their ability to provide screening. ${ }^{28-31}$ Health professionals have also been found to lack knowledge in regard to the carrier frequency of CF in the general population with only a small number of GPs believing CF carrier screening should be offered to those without a family history of the condition. ${ }^{32}$

In conclusion, the majority of participants who are currently not offered screening stated that CF carrier screening should be available in the public health system. Studies have shown that offering carrier screening for CF to pregnant women or couples planning a pregnancy is cost effective, and furthermore is more cost effective than the currently offered newborn screening for CF in Victoria, Australia. ${ }^{33}$

A major barrier to accepting an offer of screening appears to be lack of knowledge with potential participants citing lack of family history as a significant factor in their decision to decline screening. 
Health professionals offering CF carrier screening need education to provide accurate pre-test information in order for women and couples of all ethnic backgrounds to make an informed decision. Cost is a significant barrier that could be overcome with government funding that would address the current inequality of access to $\mathrm{CF}$ carrier screening.

\section{CONFLICT OF INTEREST}

The authors declare no conflict of interest.

\section{ACKNOWLEDGEMENTS}

MBD is a National Health and Medical Research Council Practitioner Fellow. This study was supported by the Victorian Government's Operational Infrastructure Support Programme. We thank Drs Veronica Tilly and Michelle Sadler, and staff at the Monash Medical Centre and Dandenong Hospital Antenatal Clinics for assistance with subject recruitment. We thank Evi Mugli for her assistance with data analysis of interviews.

1 Godard B, ten Kate LP, Evers-Kiebooms G, Aymé S: Population genetic screening programmes: principles, techniques, practices, and policies. Eur J Hum Genet 2003, 11: S49-S87.

2 Wilson JM, Jungner G: Prinicipals and practice of screening for disease. Public Health Paper, Number 34. Geneva: World Health Organisation, 1968.

3 Southern KW, Munck A, Pollitt R et al: A survey of newborn screening for cystic fibrosis in Europe. J Cyst Fibros 2007; 6: 57-65.

4 Cystic fibrosis genetic analysis consortium. Cystic fibrosis mutation database. 1989 (Accessed 12 October 2012at. http://www.genet.sickkids.on.ca./cftr/)

5 O'Sullivan BP, Freedman SD: Cystic fibrosis. Lancet 2009; 373: 1891-1904.

6 Rowe SM, Miller S, Sorscher EJ: Mechanisms of disease: cystic fibrosis. New Eng/ J Med 2005; 352: 1992.

7 Dodge JA, Lewis PA, Stanton M, Wilsher J: Cystic fibrosis mortality and survival in the UK: 1947-2003. Eur Respir J 2007; 29: 522-526.

8 Gardner J: What you need to know about cystic fibrosis. Nursing 2007; 37: 52-55.

9 Borgo G, Castellani C, Bonizzato A et al: Carrier testing program in a high-risk cystic fibrosis population in Northeastern Italy. Community Genet 1999; 2: 82-90.

10 McClaren BJ, Metcalfe SA, Aitken M, Massie J, Ukoumunne OC, Amor DJ: Uptake of carrier testing in families after cystic fibrosis diagnosis through newborn screening. Eur J Hum Genet 2010; 18: 1084-1089.

11 Krawczak M, Cooper DN, Schmidtke J: Estimating the efficacy and efficiency of cascade genetic screening. Am J Med Genet 2001; 69: 361-370.

12 Boulton M, Cummings C, Williamson R: The views of general practitioners on community carrier screening for cystic fibrosis. $\mathrm{Br} J$ Gen Pract 1996; 46: 299-301.

13 McClaren BJ, Metcalfe SA, Amor DJ, Aitken M, Massie J: A case for cystic fibrosis carrier testing in the general population. Med J Austr 2011; 194: 208-209.
14 Watson MS, Cutting GR, Desnick RJ et al: Cystic fibrosis population carrier screening: 2004 revision of American College of Medical Genetics mutation panel. Genet Med 2004; 6: 387-391.

15 American College of Obstetricians and Gynecologists Committee on Genetics. ACOG Committee Opinion No. 486: Update on carrier screening for cystic fibrosis. Obstet Gynecol 2011; 117: 1028-1031.

16 Human Genetics Society of Australasia. Cystic fibrosis population screening position paper (Document No. PSO2). Sydney: HGSA, 2010 (Accessed 4th December, 2012 at. https://http://www.hgsa.org.au/website/wp-content/uploads/2010/06/2010PS02CYSTIC-FIBROSIS-POPULATION-SCREENING1.pdf)

17 Massie J, Petrou V, Forbes R et al: Population-based carrier screening for cystic fibrosis in Victoria: the first three years experience. Aust NZ J Obstet Gynaecol 2009; 49: 484-489.

18 Ioannou L, Massie J, Collins V, McClaren B, Delatycki M: Population-based genetic screening for cystic fibrosis: attitudes and outcomes. Public Health Genomics 2010; 13: $449-456$.

19 Ioannou L, Massie J, Lewis S, McClaren BJ, Collins V, Delatycki M: No thanks-Why pregnant women choose not to have cystic fibrosis carrier screening. J Community Genet 2013; e-pub ahead of print 29 May 2013; PMID: 23715719.

20 Tambor ES, Bernhardt BA, Chase GA et al: Offering cystic fibrosis carrier screening to an HMO population: factors associated with utilization. Am J Hum Genet 1994; 55: 626-637.

21 Hall J, Fiebig DG, King MT, Hossain I, Louviere JJ: What influences participation in genetic carrier testing?. Results from a discrete choice experiment. J Health Econ 2006; 25: 520-537.

22 Clayton EW, Hannig VL, Pfotenhauer JP, Parker RA, Campbell PW 3rd, Phillips JA 3rd: Teaching about cystic fibrosis carrier screening by using written and video information. Am J Hum Genet 1995; 57: 171-181.

23 Rohlfs EM, Zhou Z, Heim RA et al: Cystic fibrosis carrier testing in an ethnically diverse US population. Clin Chem 2011; 57: 841-848.

24 McClaren BJ, Delatycki MB, Collins V, Metcalfe SA, Aitken M: 'It is not in my world': an exploration of attitudes and influences associated with cystic fibrosis carrier screening. Eur J Hum Genet 2008; 16: 435-444

25 Poppelaars FAM, van der Wal G, Braspenning JCC et al: Possibilities and barriers in the implementation of a preconceptional screening programme for cystic fibrosis carriers: a focus group study. Public Health 2003; 117: 396-403.

26 Honnor M, Zubrick SR, Walpole I, Bower C, Goldblatt J: Population screening for cystic fibrosis in Western Australia: community response. Am J Med Genet 2000; 93. 198-204.

27 Loader S, Caldwell P, Kozyra A et al: Cystic fibrosis carrier population screening in the primary care setting. Am J Hum Genet 1996; 59: 234-247.

28 Qureshi N, Armstrong S, Modell B: GPs' opinions of their role in prenatal genetic services: a cross-sectional survey. Fam Pract 2006; 23: 106-110.

29 Morgan S, McLeod D, Kidd A, Langford B: Genetic testing in New Zealand: the role of the general practitioner. NZ Med J 2004; 117: U1178.

30 Morgan MA, Driscoll DA, Mennuti MT, Schulkin J: Practice patterns of obstetriciangynecologists regarding preconception and prenatal screening for cystic fibrosis. Genet Med 2004; 6: 450-455.

31 Rowley PT, Loader S, Levenkron JC, Phelps CE: Cystic fibrosis carrier screening: knowledge and attitudes of prenatal care providers. Am J Prev Med 1993; 9: 261-266.

32 Mennie M, Campbell H, Liston WA, Brock DJH: Attitudes of general practitioners to screening for cystic fibrosis. J Med Screen 1998; 5: 11-15.

33 Norman R, van Gool K, Hall J, Delatycki M, Massie J: The cost-effectiveness of carrier screening for cystic fibrosis: approaches in Australia. J Cyst Fibros 2012; 11: 281-287. 